\title{
ARTIFICIAL NEURAL NETWORK MODELING FOR THE PREDICTION OF CRITICAL TRANSFORMATION TEMPERATURES IN STEELS
}

\author{
C. Garcia-Mateo, C. Capdevila, F.G. Caballero, and C. García de Andrés \\ MATERALIA Research Group \\ Department of Physical Metallurgy, Centro Nacional de Investigaciones Metalúrgicas (CENIM), Consejo Superior de \\ Investigaciones Científicas (CSIC), Avda. Gregorio del Amo, 8, 28040 Madrid, Spain \\ Corresponding autor: Carlos Garcia-Mateo. Tel.: +34 915538900 (ext. 364) \\ Fax.: +34 915347425. E-mail: cgm@cenim.csic.es
}




\begin{abstract}
Accurate knowledge of critical transformation temperatures in steels such as the austenitising temperature, $T_{\gamma}$, isothermal bainite and martensite start temperatures, $B_{S}$ and $M_{S}$, is of unquestionable significance from an industrial and research point of view. Therefore a significant amount of work has been devoted not only in understanding the physical mechanism lying beneath those transformations, but also obtaining quantitatively accurate models.

Nowadays, with modern computing systems, more rigorous and complex data analysis methods can be applied whenever required. Thus, Artificial Neural Network (ANN) analysis becomes a very attractive alternative, for being easily distributed, self-sufficient and for its ability of accompanying its predictions by an indication of their reliability.
\end{abstract}

\title{
Keywords
}

Artificial Neural Network (ANN), Bayesian framework, empirical analysis, austenitisation, bainite, martensite, transformation temperature 


\section{Introduction}

Historically, correlation of experimental data against chosen variables using linear regression analysis has been used when dealing with complex problems. Nowadays, in the computing era, a more powerful method of empirical analysis involves the use of ANN.

Justification for an accurate knowledge of austenitisation temperature, $T_{\gamma}$, arises when new steels and processing routes are designed, or when solid-state phase transformations are being studied, to know at which temperature the microstructure becomes completely austenitic, with no precipitates at all that may interfere with further transformations or processes such as recrystallization, is of great importance.

In a similar scheme, isothermal martensite and bainite start temperatures, $M_{S}$ and $B_{S}$, are defined as the highest temperature at which austenite starts to transform to martensite and bainite respectively. Due to the excellent combination of properties achieved by these microstructures and their wide range of applications, there is an understandable and considerable industrial interest in being able to predict, reliably, both temperatures.

The exact values of these three temperatures strongly depend on the chemical composition of the steel, and considerable work has been devoted to developing quantitative models for their compositional 
dependency. This has long been done by means of linear or polynomial regressions, that may be classified as non-adaptative methods because the shape of the functions are pre-determined by the authors rather than adapted to the data. Furthermore, such methods have very limited ranges of applicability because of their inability to deal with complex interactions. In contrast, ANN methods, as discussed later, are adaptative functions, and are able to analyze a great number of non-linear relationships of considerable complexity.

Experimental data are presented to the network in the form of input and output parameters, and the optimum non-linear relationship is found by minimizing a penalized likelihood. In fact, the network tries out many kinds of relationships in its search for an optimum fit. Similar to regression analysis, the input data $x_{i}$ are multiplied by weights, but the sum of all these products forms the argument of a flexible mathematical function, often a hyperbolic tangent. The output $y$ is therefore a non-linear function of $x_{i}$. The exact shape of the hyperbolic tangent can be varied by altering the weights. Further degrees of non-linearity can be introduced by combining several of these hyperbolic tangents, so that the ANN method is capable of capturing almost arbitrarily non-linear relationships.

On the other hand, with the development of calculation frameworks such as CALPHAD, which allow prediction of thermodynamic properties of complex systems from data collected on simpler ones, more physically relevant approaches relying on the satisfaction of some thermodynamic criteria have, also, gained importance [1,2]. This approach allows a much wider range of applicability than linear regression. Furthermore, the physical basis suggests that it should extrapolate relatively safely unless the mechanisms taken into account change significantly with composition, or the empirical thermodynamic data behave badly in extrapolation. Still these approaches suffer of some important limitations, i.e in those models some of the thermodynamic criteria used for the calculation of $M_{S}$ and $B_{\mathrm{S}}$ are model-dependent in the sense that are implicitly linked with the database that has been used during the derivation of the function to express its compositional dependency. This becomes a problem if different databases are used in deriving the criterion and in making predictions (or more exactly, if the different databases describe similar systems differently). With the increasing number of thermodynamics databases available (SGTE, SSOL, NPL plus, TCFE, Kmart) this problem cannot be neglected. In addition, the accuracy of the model may be limited by that of the underlying thermodynamic database, therefore the empirical component is not eliminated but displaced to 
lower levels of the model. Finally, making predictions requires access to expensive thermodynamic calculation software and databases.

New empirical methods such as ANN analysis, offer attractive advantages, being not only easily distributed and self-sufficient but also being able to cover arbitrarily large ranges of data. As any other method, their domain of applicability is somewhat determined by the data available at the time the model is

defined. However, a feature unique to the method employed in the present work is the ability of the model to accompany its predictions by an indication of their reliability.

It is the aim of this work to present a more accurate alternative to the classical empirical calculations of $T_{\gamma}, M_{S}$ and $B_{S}$ temperatures. In relation with the later the new models have a wider range of application, and, in some cases, alloying elements never before used in models have been introduced.

\section{Artificial neural network modeling}

\subsection{Method}

ANN in the present context, essentially refers to non-linear multiple regression tools using adaptative functions. Since the method has been described elsewhere [3-5] what follows is an emphasis of the essential and more distinctive features.

The typical structure of a neural network is presented in Fig. 1, showing that in fact it is a simple combination of transfer functions (hyperbolic tangents in our case) and weights.

\section{FIGURE 1}

A complete mathematical description of a network it might be as: the function for a network with $j$ hidden units (second-layer in Fig. 1), connecting the inputs $x_{i}$ to the output $y$ is given by

$$
y=\sum_{j} w_{j}^{(2)} z_{j}+\theta^{(2)}
$$

where: 


$$
z_{j}=\tanh \left(\sum_{i} w_{j i}^{(1)} x_{i}+\theta_{j}^{(1)}\right)
$$

where $w$ are weights and $\theta$ the constant as defined in the context of linear regression.

Training the network implies identifying an optimal set of weights, given some data for which the output is known. This is similar in principle to identifying the slope and intercept of the best fit line in a linear regression. The fundamental difference between this type of regression and methods introduced earlier is that ANN correspond to adaptative functions. In traditional methods, the author fixes the form of the equation (for example, a second degree polynomial), and identifies the parameters that lead to optimal fitting of the observed data. Even in the few cases where the authors assess more than one function (for example, to determine whether a second or third degree polynomial is most appropriate), the extent to which the function is adapted to the data is very limited.

With ANN however, the complexity of the function is mainly controlled by the weights themselves, so that the optimisation includes a determination of the most suitable shape for the function. A potential difficulty with the use of flexible non-linear regression methods is the possibility of overfitting data. In the situation e.g. of having two possible fitted functions, say a smooth curve and a non-linear polynomial function, Fig. 2, it is not possible, without any guiding physical principles relating $\mathrm{X}$ to $\mathrm{Y}$, to assess which of these functions is the more reliable in extrapolation. One method widely applied to limit overfitting, is to perform the optimisation on only one part of the data, then use the second part to determine which level of complexity best fits the data. In Fig. 2, the solid circles represent the training data, and the crosses the test data. During training of the model the best solution appears as that which goes through all the filled circles. When using the second part of the dataset (crosses), it becomes obvious, however, that this solution is strongly overfitted, the real trend is better captured by a simpler model. In Fig. 2, the training and test error trends are schematically represented as a function of the model complexity, when the later increases, not surprisingly, the training error tends to decrease continuously. In order to select which model generalizes best to unseen data, the minimum in the test error is one of the parameter used. There are other parameters which control the complexity, which are adjusted automatically to try to achieve the right complexity of the model $[6,7]$. 


\section{FIGURE 2}

\subsection{Bayesian framework}

In regression analysis it is a common practice to best fit a function to the data, i.e., to use the most probable values of the weights for a given model. Thus, by comparing the predictions against experimental values it is possible to obtain an overall error but, with no indication of the uncertainty as a function of position in the input space. There is a treatment of ANN in a Bayesian framework [6-8], which allows the calculation of error bars representing the uncertainty in the fitting parameters. Rather than identifying optimum parameter, an optimum probability distribution of parameter values is fitted to the data. This recognizes the existence of many functions which can be fitted or extrapolated into uncertain regions of the input space, without compromising the fit in adjacent regions which are rich in accurate data. The errors bars accompanying predictions become large when data are sparse or locally noisy. The Bayesian framework is also used to avoid overfitting and relevance determination [6,7]

\section{Databases}

As it was mentioned earlier, the aim of this work is to create models that describe the three temperatures, $T_{\gamma}, M_{S}$ and $B_{S}$ (both under isothermal conditions), as a function of the steel chemical composition. For this purpose an extensive bibliographic survey allowed the collection of a great number of cases where steel composition and transformation temperature/s were detailed. It is necessary to highlight the fact that in all the collected cases there was no interference of previous transformations or precipitation of any kind, meaning that austenite, from which bainite and martensite isothermally transform, has exactly the same chemical composition of that reported for the bulk material. Some of the alloy may contain minute quantities of elements such as, $\mathrm{P}$ and $\mathrm{S}$ which have not been included in the model.

For the $T_{\chi}$ temperature 
A total of 700 cases were collected mainly from "Atlas of Isothermal Transformations" [9-12]. Table I shows the list of six input variables used for the $T_{\gamma}$ analysis.

\section{TABLE I}

In comparison with the best known Andrew's model [13], the ANN model developed significantly has increased the applicability range and, as it will be shown, it is able to predict a change of tendency when the eutectoid concentration is reached.

\section{$\underline{\text { For the isothermal } B_{S} \underline{\text { temperature }}}$}

A literature survey [14-19] allowed the collection of 247 individual cases where detailed chemical composition and isothermal bainite start temperature were reported. Table II shows the list of 11 input variables used for the $B_{S}$ temperature analysis.

\section{TABLE II}

In relation to other models $[14,20,21]$ the range of compositions has been increased between $1-2$ wt.\% for C, Si, Mn and V, and more than 5 wt.\% in the case of Cr, Mo and W. Probably for the first time Al is included in a study of these characteristics.

$\underline{\text { For the isothermal } M_{\underline{S}} \text { temperature }}$

For the isothermal $M_{S}$ temperature, data were obtained from a variety of sources [10,14-16,22-38]. This resulted in a database containing about 1200 entries and covering a wider variety of compositions, Table III, when compared with existing models [14,37,39-41]. A detailed critical assessment against some published models for the $M_{S}$ temperature can be found in ref $[42,43]$

\section{TABLE III}

The procedure of database training has been described numerous times in the literature, e.g. [4]. In the present study, a commercial package [44] was used which implements the algorithm written by Mackay [7]. 


\section{Results and discussion}

Evolution of $T_{\gamma}$ temperature in Fe-C, Fe-Cr, Fe-Mo and Fe-Mn binary systems, according to the ANN model, are presented in Fig. 3.

In pure iron, carbon solubility in austenite $(\gamma)$ is much greater than in ferrite $(\alpha)$, thus in the carbon range usually encountered in steels, from 0.05 to $1.5 \mathrm{wt} \%$, the phase field associated with $\gamma$ is larger compared with that of $\alpha$, that is to say $C$ is a $\gamma$-stabilizer. Therefore transformation of $\gamma \rightarrow \alpha$ occurs via an eutectoid reaction, the eutectoid temperature and composition are $723^{\circ} \mathrm{C}$ and about $0.8 \mathrm{wt} \% \mathrm{C}$ respectively, see for example [45]. As it was anticipated, the ANN model created for the prediction of the $T_{\gamma}$ is able to predict a change in the tendency when the eutectoid point is reached, at about $750^{\circ} \mathrm{C}$ and $0.8 \mathrm{wt} . \% \mathrm{C}$, showing a good agreement with the experimental behavior just described.

On the other hand, there are elements, such as $\mathrm{Cr}$ and Mo, which fall in the category of the so called $\alpha$-stabilizers. These elements restrict the formation of $\gamma$ iron causing the $\gamma$ area of the diagram to contract to a small area referred to as the gamma loop, see ref [46] and [47] for the $\mathrm{Cr}$ and Mo cases respectively. This means that $\mathrm{Cr}$ and Mo are encouraging the formation of $\alpha$ iron, and one result is that the $\alpha$ phase field becomes continuous. Alloys in which this has taken place are, therefore, not amenable to the normal heat treatments involving cooling through the $\gamma / \alpha$ phase transformation. As it can be observed in Fig.3 the model can not predict an exact $\gamma$ loop, but clearly shows the appropriate tendency. This is explained keeping in mind that none of the steels used to build the experimental data base have an austenitisation temperature higher than $1290^{\circ} \mathrm{C}$, while the experimental data $[46,47]$ reports that the loop for $\mathrm{Fe}-\mathrm{Cr}$ and Fe-Mo diagrams closes at $1400^{\circ} \mathrm{C}$. This deficiency of data results, as it was described, in big errors bars and inaccurate predictions making impossible the prediction of a close loop but just the proper tendency. On the other hand, the model is able to predict, with a good degree of accuracy the $\mathrm{Cr}$ and Mo concentration, from where the loop starts to close, about 12 and $3.3 \mathrm{wt} . \%$ respectively [46,47].

Mn has been selected as another example of a $\gamma$-stabilizer, [48], if added in sufficiently high concentrations, completely eliminates the $\alpha$ phase and replaces it, down to room temperature, with the $\gamma$ phase. This is accurately described by the model, see predictions in Fig. 3. 


\section{FIGURE 3}

Predicted isothermal $B_{S}$ and $M_{S}$ transformation temperatures when varying $\mathrm{C}, \mathrm{Mn}, \mathrm{Cr}, \mathrm{Ni}$, Mo and $\mathrm{Si}$ concentrations for a base steel composition Fe- 0.3 C- 1 Mn- 0.3 Si- 0.6 Cr- 0.25 Mo- $0.1 \mathrm{~V}$ all in wt.\%, for automotive components, are presented in Fig. 4. The ANN model predicts that $B_{S}$ temperature is strongly influenced by all the studied elements but $\mathrm{Si}$, as has been also observed by other authors, see e.g. ref. [14,20, 21]. The big errors bars for $\mathrm{Cr}$ concentrations above 5-6 wt.\%, are a consequence of a lack of enough experimental data in that range of concentrations, therefore warning about the reliability of the prediction. In relation to $\mathrm{Si}$, it seems that up to about $0.7 \mathrm{wt} . \%$ the trend is to slightly increase the $B_{S}$, above this temperature the model predicts a subtle change in the tendency, although error bars become larger this uncertainty in $\mathrm{Si}$ effect is also observed through some of the $B_{S}$ models found in the literature; for example; Steven and Haynes [14] did not include any effect, Kunitake and Okada [49] proposed a $B_{S}$ temperature rising when increasing $\mathrm{Si}$ concentration, just in opposition with the effect proposed by Kirkaldy and Venugopalan [39]. Although not revised in this set of results, the model predicts that $\mathrm{Co}, \mathrm{Al}$ and $\mathrm{V}$, in increasing quantities, increase the $B_{S}$ temperature, see [50].

In a similar scheme, $M_{S}$ transformation temperature is influenced by the presence of increasing quantities of $\mathrm{C}, \mathrm{Mn}, \mathrm{Cr}, \mathrm{Ni}$ and $\mathrm{Mo}$, again the model reflects well known steel metallurgical facts $[13,14,35,37,40]$. In relation to $\mathrm{Si}$ the model predicts nearly no change in the $M_{S}$, equivalent to the $B_{S}$ temperature the effect of silicon on the martensite start temperature is uncertain. In some cases Si has been found to decrease the $M_{S}$ temperature [37,40] but some other authors [14,35] reported no influence on it.

\section{FIGURE 4}

The performances of the models created were assessed on the sets of data unseen during training. Fig. 5 shows the performance of the three models in this dataset, showing that agreement with experimental data is very good, exhibiting $\mathrm{R}^{2}$ values (square of the Pearson product moment correlation coefficient) close to 1 for the $B_{S}$ and $M_{S}$ models, and about 0.9 for the $T_{\gamma}$.

FIGURE 5 
Finally it is necessary to touch upon the unique feature of the frame work used for the ANN models, to accompany its predictions with an indication of the uncertainty as a function of position in the input space, big errors bars where there is a lack of enough experimental data, as it has been already shown through this last section.

\section{Conclusions}

A very large data base has been used to create three ANN models capable of predicting $T_{\gamma}, B_{S}$ and $M_{S}$ temperatures. This technique plus a Bayesian framework have been chosen for its flexibility and ability of accompanying its predictions with an estimation of the uncertainty.

The analysis is empirical, but after appropriate training, it is found to reliably reproduce known metallurgical experience. The method is useful because the optimized network summarizes knowledge in a quantitative manner and can be retrained as new data became available. Those models are different to those empirical and semi-empirical models created by fitting equations to experimental data.

\section{Aknowledgements}

The authors acknowledge financial support from the European Coal and Steel Community (ECSC agreement number 7210-PR/345) and the Spanish Ministerio de Ciencia y Tecnología (Project-MAT 200210812 E). C. Garcia-Mateo would like to thank Spanish Ministerio de Ciencia y Tecnología for the financial support in the form of a temporal Ramón y Cajal contract (RyC 2004 Program). 


\section{References}

[1]. G.B. OLSON and M. COHEN, Metall. Trans. 7A (1976) 1897.

[2]. H.K.D.H. BHADESHIA, in "Bainite in Steels" (2nd ed. Institute of Materials, London, 2001).

[3]. D.J.C. MACKAY in "Information Theory, Inference, and Learning Algorithms" (Cambridge University Press, Cambridge 2003).

[4]. H.K.D.H BHADESHIA, ISIJ Int. 39 (1999) 966.

[5]. T. SOURMAIL, H.K.D.H. BHADESHIA and D.J.C. MACKAY, Mater Scie. Techn. 18 (2002) 655.

[6]. D.J.C. MACKAY, Neural Computation. 4 (1992) 415.

[7]. D.J.C. MACKAY, Neural Computation. 4 (1992) 448.

[8]. T. SOURMAIL and H.K.D.H. BHADESHIA in "Introduction to Materials Modeling" (ed. Z. Barber, Institute of Materials, London 2005).

[9]. “Atlas of Isothermal Transformation Diagrams" (United States Steels, USS, Corporation, Pittsburgh 1959).

[10]. M. ECONOMOPOULOS, N. LAMBERT and L. HABRAKEN, in "Diagrammes de Transformation des Aciers Fabriques dans le Benelux" (Ed. Centre National de Recherches Metallurgiques (CRM), Bruxelles 1967).

[11]. F. MARATRAY and R. USSEGLIO-NANOT in "Atlas of Transformation Characteristics of Chromium and Chromium-Molybdenum White Irons" (Climax Molybdenum S.A., Paris, France 1996).

[12]. M. ATKINS in "Atlas of Transformation Diagrams for Engineering Steels" (British Steel Coorporation, BSC, Sheffield, England 1985).

[13]. K.W. ANDREWS, JISI. 203 (1965) 721.

[14]. W. STEVEN and A.G. HAYNES, JISI, 183 (1956) 349. 
[15]. H.E.BOYER in "Atlas of Isothermal transformation and cooling transformation diagrams" (American Society of Metals. Metals Park, Ohio 44073 1977).

[16]. "Atlas of Isothermal transformation of B.S. En Steels" (2nd edition. Special report No. 56. The Iron and steel Institute. 4 Grosvenor gardens, London, SWI. 1956).

[17]. L.C. CHANG. Metall. Trans. A. 30 (1999) 909.

[18]. C. GARCIA-MATEO, F.G. CABALLERO and H.K.D.H. BHADESHIA, ISIJ Int. 43 (2003) 1821.

[19]. G.F. VANDER VOORT (ed) in "Atlas of Time-temperature diagrams for Irons and Steels" (ASM International, Metals Park, OH, 1991).

[20]. Y.K. LEE, J Mater Sci Letters. 21 (2002) 1253.

[21]. R.L. BODNAR, T. OHHASHI and R.I. JAFFEE, Metall. Trans. A. 20 (1989) 1445.

[22]. G.GHOSH and G.B. OLSON, Acta Mat. 42 (1994) 3361.

[23]. M.ATKINS in "Atlas of continuous cooling transformation diagrams for engineering steels" (Tech. Rep. British Steel Corporation 1998).

[24]. "Atlas of isothermal transformation diagrams of B.S. EN steels (Special report no 40, Tech. rep., The British Iron and Steel research association 1949)

[25]. A.B. GRENINGER, Trans. ASM 30 (1942) 1..

[26]. T.G. DIGGES, Trans. ASM 28 (1940) 575.

[27]. T.BELL and W.S. OWEN, JISI 205 (1967) 1777.

[28]. K.ISHIDA and T.NISHIZAWA, Trans. JIM 15 (1974) 218.

[29]. M.OKA and H.OKAMOTO, Metall. Trans. A 19 (1988) 447.

[30]. J.S. PASCOVER and S.V. RADCLIFFE, Trans. AIME 242 (1968) 673.

[31]. R.B.G. YEO, Trans AIME 227 (1963) 884. 
[32]. A.S. SASTRI and D.R.F. WEST, JISI 203 (1965) 138.

[33]. U.R. LENEL and B.R. KNOTT, Metal. Trans. A 18 (1987) 767.

[34]. R.H. GOODENOW and R.F. HEHEMAN, Trans. AIME 233 (1965) 1777.

[35]. R.A. GRANGE and H.M. STEWART, Trans. AIME 167 (1945) 467.

[36]. M.M. RAO and P.G. WINCHELL, Trans. AIME 239 (1967) 956.

[37]. P.PAYSON and C.H. SAVAGE, Trans. ASM 33 (1944) 261.

[38]. E.S. ROWLAND and S.R. LYLE, Trans. ASM 37 (1946) 27.

[39]. J.S. KIRKALDY and D. VENUGOPALAN in "Phase Transformations in Ferreous Alloys" (Ed. by A. R. Marder y J.I. Goldstein, TMS-AIME, Warrendale, PA, 1984).

[40]. L. A. CARAPELLA. Metals Progress 46 (1944) 108.

[41]. W.G. VERMEULEN, P.F. MORRIS, A.P. DE WEIJER and S. VAN DER ZWAAG. Ironmaking and Steelmaking 23 (1996) 433.

[42]. T. SOURMAIL and C. GARCIA-MATEO. Compu. Mater. Sci. 34 (2005) 323.

[43]. T. SOURMAIL and C. GARCIA-MATEO. Compu. Mater. Sci. 34 (2005) 213.

[44]. “Model Manager. Neuromat Ltd” www.neuromat.com (2003).

[45]. R.W.K. HONEYCOMBE and H.K.D.H. BHADESHIA, in "Steels. Microstructure and Properties" (2nd ed. Edward Arnold, London, 1995).

[46]. J-O. ANDERSSON and R. SUNDMAN. Calphad 11 (1987) 83.

[47]. A. FERNANDEZ GUILLERMET. Calphad 6 (1982) 127.

[48]. W. HUANG. Calphad 13 (1989) 243.

[49]. T. KUNITAKE and Y. OKADA. J. Iron and Steel Inst. Japan 84 (1998) 137. 
[50]. C. GARCIA-MATEO, T. SOURMAIL, F.G. CABALlERO, C. CAPDEVILA and C. GARCIA DE ANDRÉS. Mater. Sci. Tech. 21 (2005) 934.

\section{Tables}

Table I. Input variables of database for $T_{\gamma}$ temperature model. Concentrations are in wt.\%.

\begin{tabular}{ccccccc}
\hline & $\mathrm{C}$ & $\mathrm{Mn}$ & $\mathrm{Si}$ & $\mathrm{Ni}$ & $\mathrm{Cr}$ & $\mathrm{Mo}$ \\
\hline Min. & 0.00 & 0.00 & 0.00 & 0.00 & 0.00 & 0.00 \\
Max. & 2.09 & 20.00 & 3.40 & 40.00 & 18.39 & 5.09 \\
\hline
\end{tabular}

Table II. Input variables of database for $B_{S}$ temperature model. Concentrations are in wt.\%. 


\begin{tabular}{ccccccccccccc}
\hline & $\mathrm{C}$ & $\mathrm{Si}$ & $\mathrm{Mn}$ & $\mathrm{Ni}$ & $\mathrm{Cr}$ & $\mathrm{Mo}$ & $\mathrm{Cu}$ & $\mathrm{Al}$ & $\mathrm{V}$ & $\mathrm{W}$ & $\mathrm{Co}$ \\
\hline & Min. & 0.11 & 0 & 0 & 0 & 0 & 0 & 0 & 0 & 0 & 0 & 0 \\
Max. & 1.5 & 1.67 & 3.76 & 5.04 & 11.5 & 8 & 0.26 & 0.99 & 2.1 & 18.59 & 5 \\
\hline
\end{tabular}

Table III. Input variables of database for $M_{S}$ temperature model. Concentrations are in wt.\%.

\begin{tabular}{ccccccccccccccccc} 
& $\mathrm{C}$ & $\mathrm{Si}$ & $\mathrm{Mn}$ & $\mathrm{Ni}$ & $\mathrm{Cr}$ & $\mathrm{Mo}$ & $\mathrm{Cu}$ & $\mathrm{Al}$ & $\mathrm{V}$ & $\mathrm{W}$ & $\mathrm{Co}$ & $\mathrm{Cu}$ & $\mathrm{Nb}$ & $\mathrm{Ti}$ & $\mathrm{B}$ & $\mathrm{N}$ \\
\hline Min. & 0.0 & 0.0 & 0.0 & 0.0 & 0.0 & 0.0 & 0.0 & 0.0 & 0.0 & 0.0 & 0.0 & 0.0 & 0.0 & 0.0 & 0.0 & 0.0 \\
Max. & 2.2 & 3.8 & 10.2 & 31.54 & 17.9 & 8.0 & 3.04 & 3.01 & 4.55 & 18.5 & 30.0 & 3.0 & 1.9 & 2.5 & 0.06 & 2.6 \\
\hline
\end{tabular}

\section{Figures legends}

Figure 1. The typical structure of a neural network as used for non-linear multiple regressions. The first layer is made up by the inputs $\left(1, . ., \mathrm{x}_{\mathrm{i}}\right)$, the second by so-called 'hidden units' and the last one is the output. 
Figure 2. Schematic illustrations of the overfitting problem in ANN and, variation in the test and training errors as a function of the model complexity.

Figure 3. Evolution of $T_{\gamma}$ in Fe-X diagrams, where $\mathrm{X}$ stands for $\mathrm{C}, \mathrm{Cr}$, Mo and $\mathrm{Mn}$. Solid lines represent the model predictions; meanwhile dashed lines represent the error bounds

Figure 4. $B_{S}$ and $M_{S}$ predictions for a steel of base composition Fe- $0.3 \mathrm{C}-1 \mathrm{Mn}-0.3 \mathrm{Si}-0.6 \mathrm{Cr}-0.25 \mathrm{Mo}-0.1 \mathrm{~V}$ in wt.\%.

Figure 5. Performance of the three models on a test dataset of unseen data during training. 


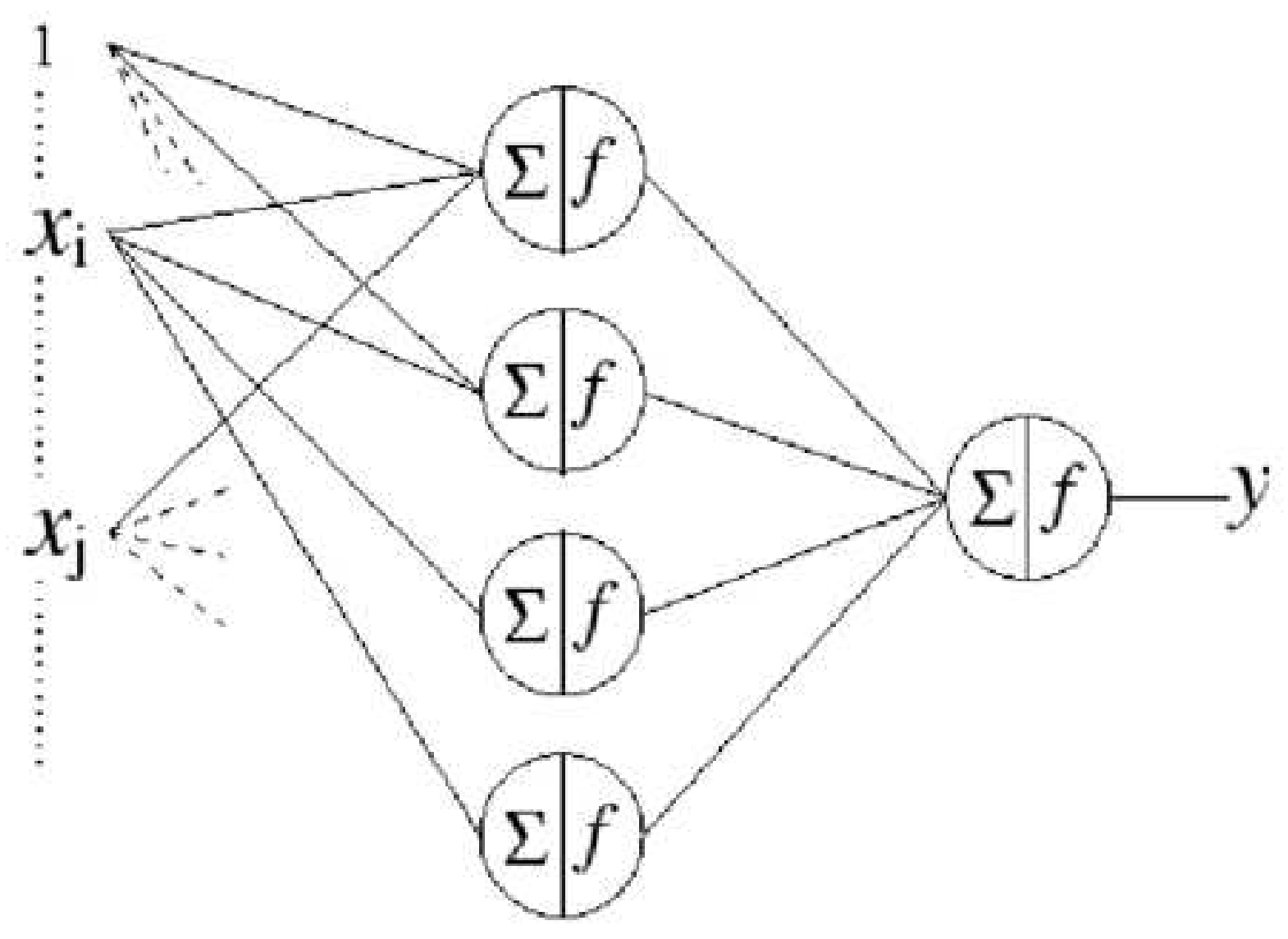

Figure_1 

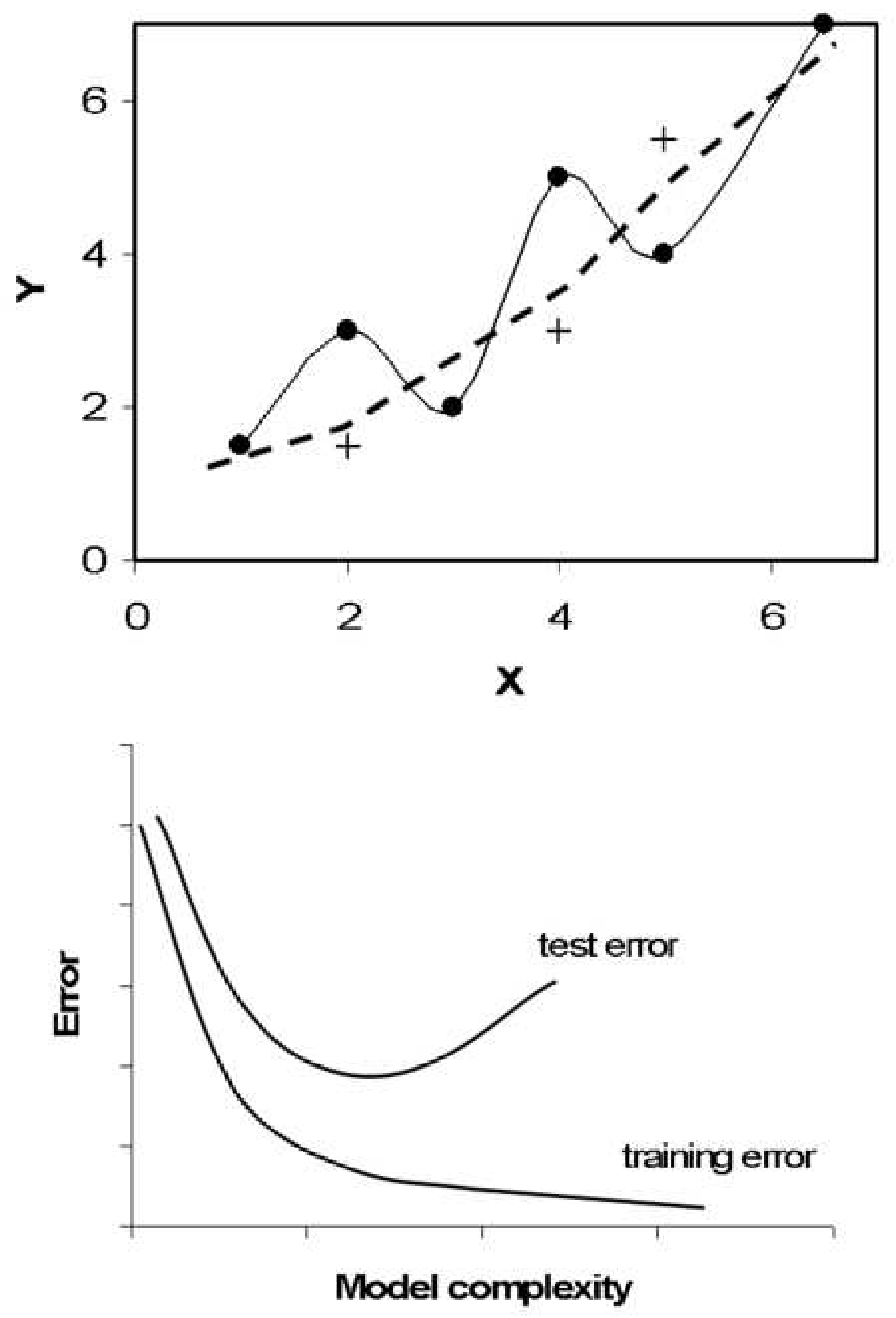

Figure_2

(⿸丆口

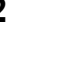
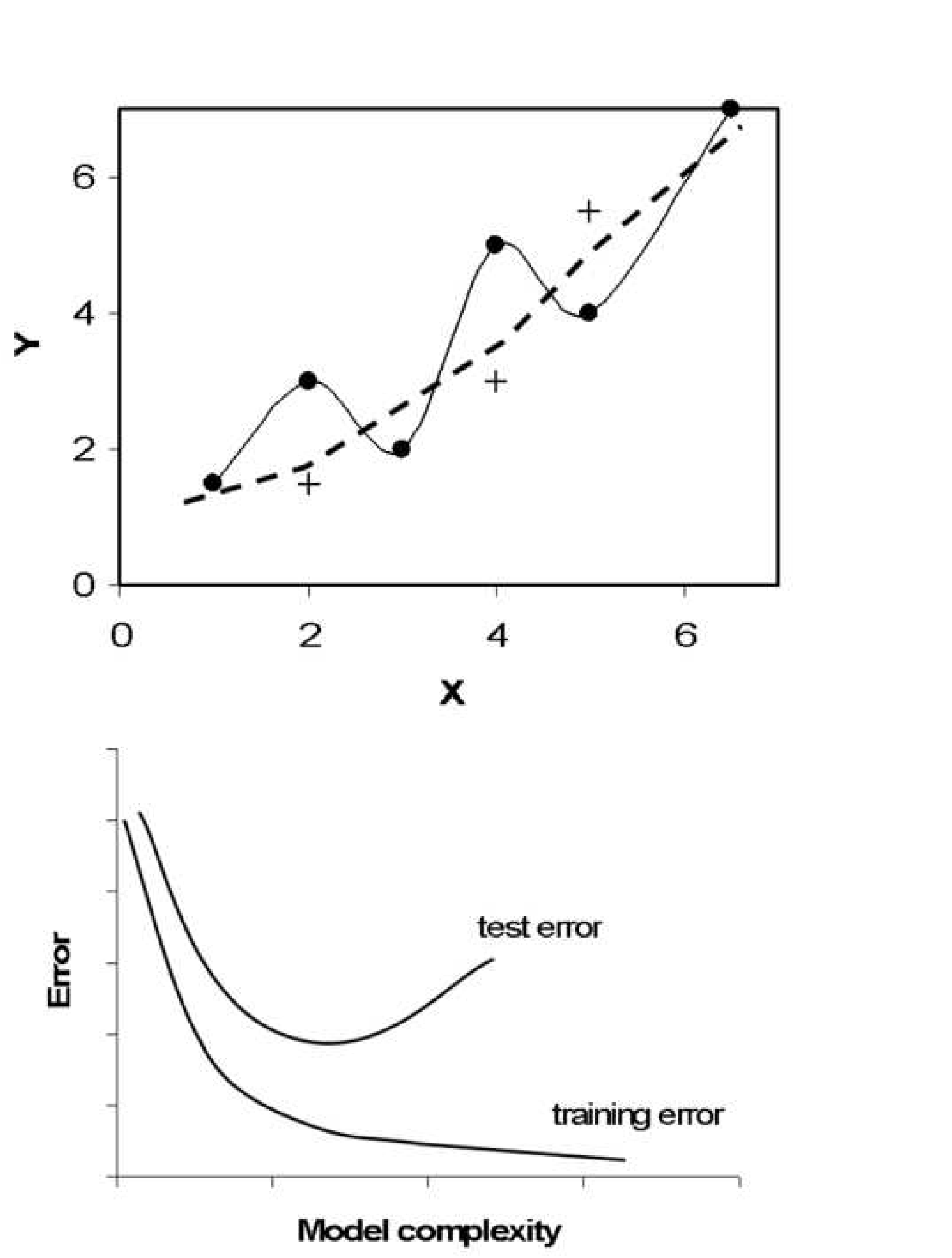
Figure_3
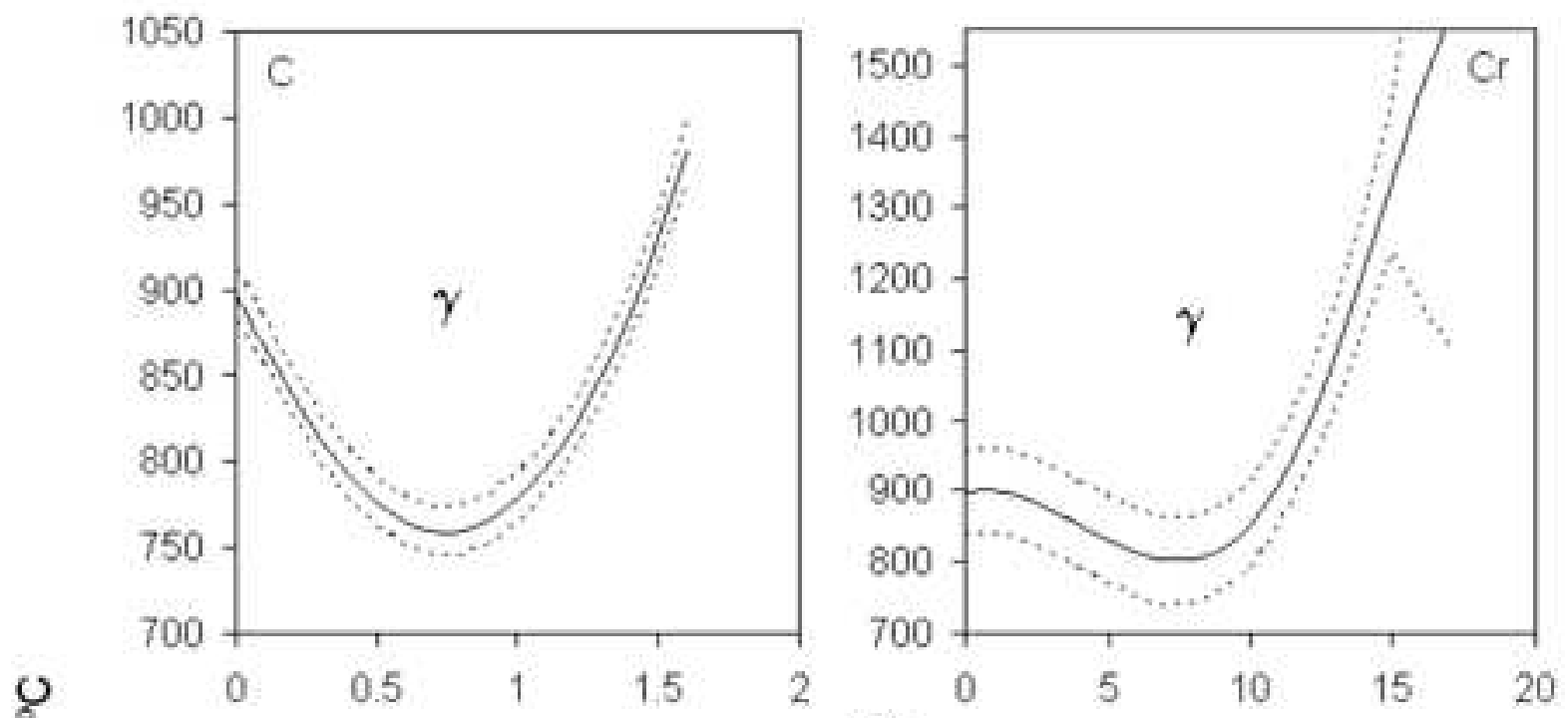

$\mathfrak{r}^{2}$
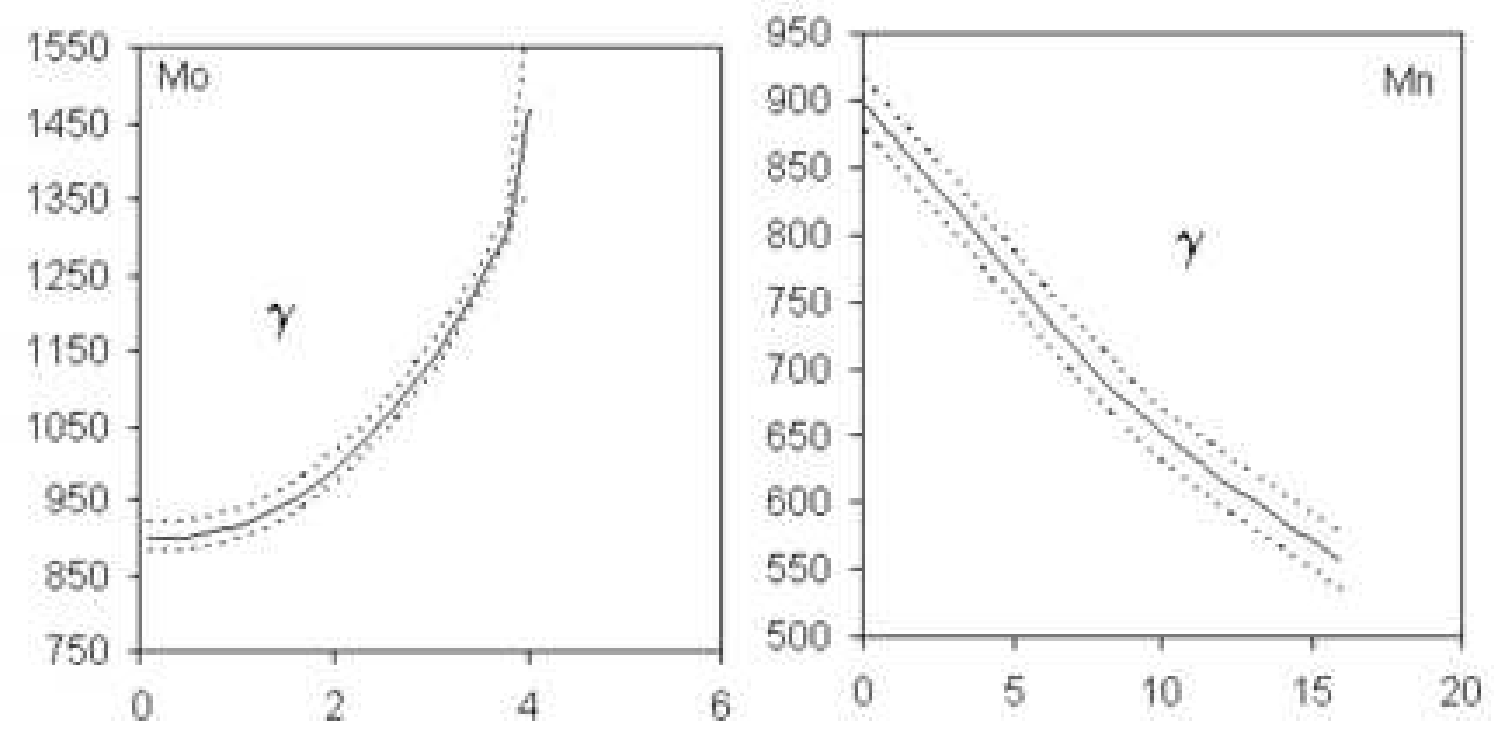

Concentration/ wt. \% 

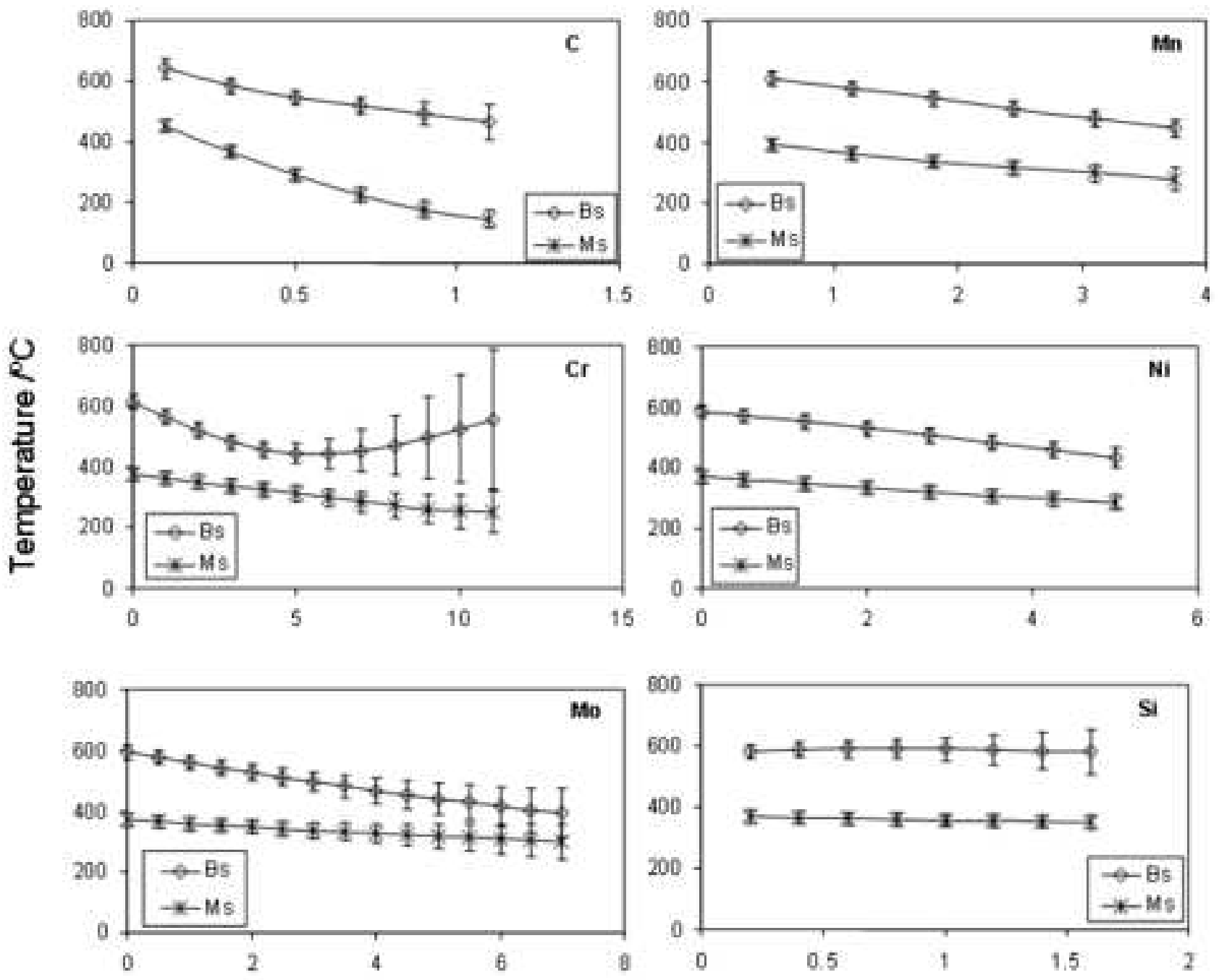

Concentration $/ \mathrm{wt} . \%$ 
